\title{
Uma introdução à CIF - Classificação Internacional de Funcionalidade, Incapacidade e Saúde
}

\author{
An introduction to the International Classification of Functioning, \\ Disability and Health
}

\author{
${ }^{1}$ Centro Colaborador da OMS \\ para a Família de Classificações \\ Internacionais em Português. \\ Departamento de Epidemiologia \\ da Faculdade de Saúde Pública da \\ Universidade de São Paulo. \\ Contato: \\ Dra. Heloisa B. V. Di Nubila \\ Faculdade de Saúde Pública/USP \\ Av. Dr. Arnaldo, 715 - São Paulo, SP \\ CEP: 01246-904 \\ E-mail:
}

hdinubil@usp.br
Recebido: 01/03/2010

Aprovado: 08/03/2010
A CIF (Classificação Internacional de Funcionalidade, Incapacidade e Saúde)* é hoje o modelo da Organização Mundial da Saúde (OMS) para saúde e incapacidade, constituindo a base conceitual para definição, mensuração e formulação de políticas nesta área.

A CIF pertence à “família” das classificações internacionais da OMS para aplicação em vários aspectos da saúde. Nesta "família”, os estados de saúde (doenças, distúrbios, lesões etc.) são classificados na CID-10 (Classificação Estatística Internacional de Doenças e Problemas Relacionados à Saúde, $10^{\underline{a}}$ revisão), enquanto a funcionalidade e a incapacidade associadas aos estados de saúde são classificadas na CIF. As duas classificações são complementares e devem ser utilizadas em conjunto, pois a CID-10 fornece um "diagnóstico" de doenças, distúrbios ou outras condições de saúde, e estas informações são complementadas pelas informações sobre funcionalidade fornecidas pela CIF.

A CIF classifica “domínios” da saúde e "domínios” relacionados à saúde, que nos ajudam a descrever alterações ou mudanças na função e na estrutura corporal, o que uma pessoa com uma condição de saúde pode fazer em um ambiente padrão (seu nível de capacidade), assim como o que ela de fato faz no seu ambiente real (seu nível de desempenho). Estes domínios são classificados a partir de perspectivas do corpo, individuais e sociais, por meio de duas listas: uma lista de funções e estruturas corporais e uma lista de atividades e participação. O termo funcionalidade refere-se a todas as funções corporais, atividades e participação, enquanto incapacidade é um termo abrangente para "deficiências, limitação de atividades ou restrições à participação”. Há também uma lista de fatores ambientais que interagem com todos estes componentes e que são muito importantes para determinar a funcionalidade/incapacidade de um indivíduo ao serem representados como barreiras ou facilitadores. A incapacidade pode ser melhor entendida como a interação negativa entre um indivíduo com uma determinada condição de saúde e os seus fatores contextuais (fatores ambientais e pessoais).

A CIF é baseada num modelo de incapacidade que poderia ser chamado de modelo biopsicossocial. Este modelo sintetiza o que é verdadeiro nos modelos médico e social, ou seja, não comete o erro de reduzir a noção de incapacidade a apenas um dos seus aspectos. A CIF fornece, por esta síntese, uma visão coerente de diferentes perspectivas da saúde: biológica, individual e social.

Os componentes da CIF se interligam e compõem um modelo multidimensional, multidirecional e dinâmico. Com este modelo, pode-se inverter a compreensão da incapacidade a partir da doença ou da condição de saúde, entendendo, ao

* ORGANIZAÇÃO MUNDIAL DA SAÚDE. CIF: Classificação Internacional de Funcionalidade, Incapacidade e Saúde. Tradução Centro Colaborador da Organização Mundial da Saúde para a Família de Classificações Internacionais. São Paulo: Edusp, 2003. 
contrário, o ambiente, levando à incapacidade e à doença. O respeito às múltiplas dimensões envolvidas no processo de saúde e funcionalidade/incapacidade (biológica, individual, social), além do reconhecimento do importante papel do ambiente (não só físico, mas social e de atitudes), traz uma nova luz sobre "saúde" e "incapacidade”, em especial sobre questões de Saúde do Trabalhador.

A CIF reconhece que todo ser humano pode experimentar uma perda ou diminuição na sua saúde e, portanto, experimentar alguma incapacidade. Isto não é algo que acontece somente a uma minoria da humanidade, mas é uma experiência humana universal. Mudando o foco da causa para o impacto, todas as condições de saúde são colocadas em pé de igualdade, permitindo que sejam comparadas, usando uma medida comum, uma escala de saúde e de incapacidade.

O “diagnóstico” sozinho não prevê a necessidade de serviços, tempo de hospitalização, nível de cuidados ou resultados funcionais. A presença de uma doença ou distúrbio também não é um bom preditor para o recebimento de benefícios por incapacidade, desempenho para o trabalho, potencial para o retorno ao trabalho ou mesmo de integração social. Isto significa que, se usarmos uma classificação médica de diagnósticos sozinha, não teremos a informação necessária para propósitos de gerenciamento e planejamento de saúde.

A CIF permite coletar dados vitais sobre tipos e níveis de funcionalidade e incapacidade de modo consistente e comparável internacionalmente, fornecendo a base para compor dados em nível nacional, ajudando a guiar o desenvolvimento de políticas nesta área.

Sabemos que, progressivamente, a CIF vem sendo conhecida e que cada vez mais os profissionais de saúde, em especial das áreas de reabilitação e, em particular, da área de reabilitação profissional, vêm se apropriando do entendimento deste modelo, o que amplia a possibilidade de pensar em novas intervenções, bem como em políticas mais voltadas à realidade das complexas relações dentro do tema "saúde e incapacidade/funcionalidade no trabalho”. Este número temático da RBSO (“Incapacidade, Reabilitação Profissional e Saúde do Trabalhador”), com certeza, faz parte e representa muito bem este processo. 